\title{
CONSTRUÇÃO DE UM VEÍCULO TERRESTRE NÃO TRIPULADO A PARTIR DE SUCATA ELETRÔNICA, MOVIDO À ENERGIA SOLAR
}

Jaime dos Santos Filho ${ }^{1}$, Salomão Savio Batista ${ }^{2}$, Junior Felix do Nascimento ${ }^{3}$, Rogério da Silva Fiscina ${ }^{4}$, Murilo Cardoso Mendes ${ }^{5}$, Daiane Oliveira Carvalho

$$
\text { 1, 2, 3, 4, 5, } 6 \text { Instituto Federal da Bahia - Vitória da Conquista }
$$

\section{jaime@ifba.edu.br,salomao.batista@ifba.edu.br,jrfelix77@hotmail.com,rogfiscina@yahoo.com.br,mur} ilof22@yahoo.com.br, daianne oliveira@hotmail.com

\section{RESUMO}

A demanda por sistemas robóticos é cada vez maior, entre estes sistemas encontram-se os veículos terrestres não tripulados que são robôs utilizados como uma extensão dos recursos humanos. Esses veículos podem ser controlados à distância e funcionar sem a intervenção humana. O desenvolvimento de um veículo autônomo envolve, primordialmente, o controle automático de seus mecanismos básicos de condução: aceleração, frenagem, direção e câmbio. $O$ objetivo desse trabalho é a descrição da construção física de um veículo autônomo e da implementação de um sistema de controle para o acionamento dos motores de corrente contínua. A estrutura foi configurada em um formato retangular com medidas na ordem de $25 \times 40 \times 8 \mathrm{~cm}$, sendo as hastes confeccionadas em perfil de alumínio tipo cantoneira. Os componentes de montagem do sistema mecânico (rodas, eixo, transmissão de velocidade e força) e motores elétricos foram utilizados da impressora fiscal da marca Bematech modelo MP-20 F1F2 ECF-1F. O sistema de controle para acionamento dos motores foi feito utilizando a plataforma arduino. Será implementado um sistema com sensores de presença por ultrassom e câmera de vídeo, para detectar a distância em relação a objetos e obstáculos. Para suprimir a demanda elétrica do motor será projetado um carregador de pilhas, senod alimentado por células fotovoltaicas.

Palavras-chave: arduino, sistema de controle, automação, energia renovável.

\section{INTRODUÇÃO}

A automação pode ser definida como: sistema automático de controle pelo qual os mecanismos verificam seu próprio funcionamento, efetuando medições e introduzindo correções, sem a necessidade da interferência do homem. $\mathrm{Na}$ automação são aplicadas técnicas computadorizadas ou mecânicas para diminuir o 
uso de mão de obra em qualquer processo, especialmente o uso de robôs nas linhas de produção. De acordo com [1], a automação pode ser definida como a tecnologia que se ocupa da utilização de sistemas mecânicos, eletro-eletrônicos e computacionais na operação e controle da produção, sendo a robótica uma forma de automação de sistemas. Para [2], o controle de um processo industrial de modo automático em vez de manual é chamado de automação.

Os Veículos Terrestres Não Tripulados (VTNTs) podem ser definidos como robôs que são utilizados como uma extensão dos recursos humanos.

Este tipo de robô é geralmente capaz de explorar de forma independente uma grande variedade de terrenos, funcionando como instrumento de pesquisa e monitoramento a lugares e regiões inóspitas ou perigosas aos seres humanos.

Esses veículos são controlados à distância, por meios eletrônicos e computacionais, sob a supervisão e monitoramento humanos, ou sem a sua intervenção, por meio de Controladores Programáveis (CPs).

Como exemplo desses CPs tem-se o arduino, que consiste em um projeto de software e hardware integrados. Seu objetivo é fornecer uma plataforma fácil e acessível para a prototipagem de projetos interativos, utilizando um microcontrolador Atmel AVR, que funciona como "cérebro" do circuito. O arduino faz parte do que se chama de computação física: área da computação em que o software interage diretamente com o hardware, tornando possível a integração com diversos periféricos como sensores e motores.

A indústria automotiva vem passando por um período de incorporação de tecnologias embarcadas aos seus produtos. Tendo como finalidade aproximar os usuários das novas tecnologias, atendendo assim as necessidades referentes a conforto, segurança, acessibilidade, mobilidade e até de "inclusão e re-inclusão social", por exemplos, de seres humanos com deficiências físicas. O que justifica a ideia e concepção da existência de um Veiculo Não Tripulado (VNT). Esses requisitos passam a ser alcançados a partir do conhecimento e interação criados entre usuários e novas tecnologias.

O arduino por constituir-se de uma plataforma de prototipagem eletrônica livre, vem sendo amplamente utilizado, a nível mundial, em projetos de automação que necessitam de ferramentas acessíveis, com baixo custo, flexibilidade e fáceis de usar. Com estas características ele pode ser usado por um público com diferentes graus de interesse e conhecimento em eletrônica e linguagem de programação.

A independência da plataforma permite a criação de projetos interativos, desde a atividade mais simples como acender um diodo emissor de luz até a criação de sistemas de automação complexos, como robôs dotados de recursos de mobilidade e de sensoriamento, para coleta de dados e tratamento de imagens. 
$\mathrm{Na}$ caminhada rumo ao desenvolvimento de tais sistemas, os VNTs vem ganhando cada vez mais espaço, seja em pesquisas realizadas nos centros de militares ou em universitários de diferentes regiões do mundo.

Num contexto mundial, por exemplo, a preocupação dos governos em relação a perdas humanas em conflitos, tem gerado o investimento em pesquisas de caráter militar, tendo como objetivo a criação de VNTs para cumprir missões desde reconhecimento de território inimigo, identificação de tropas, transporte de arsenal bélico até ataque a tropas inimigas. Para se ter uma ideia de quanto promissor vem sendo tais investimentos, na área naval, os VNTs tem se tornado mais atrativos em operações que evitem riscos para plataformas tripuladas e tarefas difíceis. Estes já estão sendo utilizados nas operações anti-minas navais com navios substituindo os caça minas e os ROVs (Remote Operated Vehicle) substituindo as equipes de mergulhadores.

No setor aéreo, os Veículos Aéreos Não Tripulados (VANTs), foram inicialmente concebidos para fins militares. Eles foram inspirados nas bombas voadoras alemãs, e hoje vem sendo projetados e construídos para serem utilizados em missões muito perigosas, nas áreas de inteligência, apoio e controle de tiro de artilharia, apoio aéreo as tropas de infantaria e cavalaria no campo de batalha, controle de misseis de cruzeiro, atividades de patrulhamento urbano, costeiro, ambiental e de fronteiras, atividades de busca e resgate etc.

O Departamento de Engenharia Mecatrônica e Sistemas Mecânicos (PMR), da Escola Politécnica da USP vêm desenvolvendo recentemente dois pequenos veículos subaquáticos. Um deles, o Pirajuba, poderá ser empregado para a coleta de dados sobre a qualidade da água e o mapeamento do solo marinho e para pesquisas oceanográficas, além de missões para inspeção de instalações submersas, como oleodutos, gasodutos e emissários submarinos. O Mandi foi desenvolvido para ser usado na realização de inspeções em turbinas submersas de usinas hidrelétricas, com mais segurança e menor custo que o mesmo trabalho feito por mergulhadores [3]. No setor aéreo a Força Aérea Brasileira já opera o VANT Hermes 450, da Elbit, e já possui parceria com a EMBRAER para o desenvolvimento do Harpia. Um VANT é em sua maioria dos casos controlado através de ondas eletromagnéticas (rádio, satélite) por uma estação em terra, contudo os projetos mais recentes possuem sistemas que permite ao VANT autonomia em caso de perda de sinal com a base [4]. Professores e estudantes do departamento de informática da Universidade Federal do Espírito Santo apresentaram uma prévia de um veiculo autônomo, em escala real, que desvia de obstáculos por meio de sensores, ausentando o motorista da função de guiá-lo. Segundo os pesquisadores, o que os motivou na criação do protótipo foi a ideia de auxiliar pessoas que possuam algum tipo de limitação para locomoção [5].

Considerando os conceitos supracitados, percebe-se que o interesse, no Brasil, pela criação de sistemas de automação dotados de independência vem sendo promissor, o que justifica o objetivo desse projeto que é da construção de um sistema autônomo, mais especificamente, um sistema baseado em veículo autônomo a partir de sucata eletrônica, movido à energia solar. 


\section{2 - METODOLOGIA}

Para a construção do robô, o passo inicial foi definir a estrutura mecânica. A primeira perspectiva do projeto mecânico é estudar a melhor maneira de produzir a estrutura capaz de suportar a carga dos componentes e possuir um menor peso possível, advindo à ideia de que quanto menor o peso menor a necessidade de energia e maior será a autonomia.

Partindo desta ideia o protótipo foi configurado em um formato retangular, com uso de perfis de alumínio do tipo cantoneira $25 \times 4 \mathrm{~mm}$, com medidas na ordem de $25 \mathrm{~cm}$ de largura, $40 \mathrm{~cm}$ de comprimento e $8 \mathrm{~cm}$ de altura.

Após a fabricação da estrutura mecânica do carro foram feitas às medições do perfil de alumínio, com cortes retos, sendo empregado arco de serra e serra manual para o corte de aço das peças citadas.

Para a montagem da estrutura foi necessário fazer duas secções de furos, com broca de cerca de $4 \mathrm{~mm}$, em cada vértice dos quatro cantos da estrutura. Para fixar a estrutura foram utilizados rebites de mesmo diâmetro. Os rebites foram dimensionados a partir do carregamento e selecionados quanto ao diâmetro da broca.

A próxima etapa foi o desmonte de quatro impressoras fiscais e seleção dos componentes. Em seguida foram realizadas técnicas de corte e limagem, com lima para aço no formato achatada, empregadas para as devidas adequações das peças selecionadas ao projeto.

Foram utilizadas impressoras fiscais da marca Bematech, modelo MP-20 F1F2 ECF$1 \mathrm{~F}$. Elas possuiam eixos estriados com diâmetro de $6 \mathrm{~mm}$, rodas de borracha acopladas ao mesmo para a movimentação do papel, polias com diâmetros de 10 $\mathrm{mm}$, acopladas a estas engrenagens de $20 \mathrm{~mm}$, correia dentada de $170 \mathrm{~mm}$, chavetas de diâmetro $10 \mathrm{~mm}$. Sua estrutura metálica é dividida em duas partes, uma como suporte e outra como base do eixo, com dimensões de $3 \mathrm{~cm}$ de largura por 10 $\mathrm{cm}$ de comprimento e $8 \mathrm{~cm}$ de largura por $4 \mathrm{~cm}$, comprimento de $8 \mathrm{~cm}$ e altura de $2,5 \mathrm{~cm}$ respectivamente.

Para a montagem do sistema mecânico foram selecionados os componentes: rodas, correia, eixos e motores elétricos. Para a transmissão de velocidade e força foi necessária a fixação de polias e correias aos eixos e ao motor, em um conjunto único.

O sistema de transmissão foi colocado na estrutura de alumínio do carro. Sendo fixado um na parte traseira, de modo a não permiti a realização de movimentos rotacionais e outro na dianteira, este com a possibilidade de movimentação rotacional. 
Para a fixação dos eixos estriados foi necessário o uso de molas, cuja função é resguardar, em casos de irregularidade do terreno, a perfeita fixação da roda ao conjunto mecânico.

$\mathrm{Na}$ fixação do sistema de transmissão do motor foram utilizadas engrenagens de plástico associadas ao eixo de rodas e uma correia dentada capaz de encaixar a engrenagem ao motor.

Um problema encontrado durante a fixação do motor e do eixo das rodas a estrutura do carro foi a diferença existente entre os diâmetros destes eixos. Este problema foi resolvido com a utilização de parte da carcaça interna da impressora. Utilizou-se parte da impressora em que fica localizava bobina de papel, devido a sua concavidade.

Com o uso de juntas de fixação colocamos o motor e o eixo de rodas, como um conjunto único, vide Figura 1.

Figura 1: Fixação do sistema motor-eixo de rodas.

Para evitar o deslocamento lateral do conjunto motor e o eixo de rodas foi necessário implementar um sistema que proporcionasse um esforço contrário a este deslocamento, caso o carrinho fosse verticalizado. A solução encontrada foi a utilização de um sistema de três molas, onde foram pressas as rodas a estrutura de ligação do eixo ao motor.

Diante da possibilidade do veículo ser utilizado em diversos tipos de terrenos e para propiciar um espaço melhor entre as rodas e a estrutura, foram fixadas molas distribuídas ao longo da estrutura. Estas foram fixadas por parafusos, arruelas e porcas, tendo como objetivo exercer a mesma função de um amortecedor. 
Amortecendo o impacto provocado pelas irregularidades do terreno, cuja força era compensada pela distensão da mola, conforme pode ser observado na Figura 2.

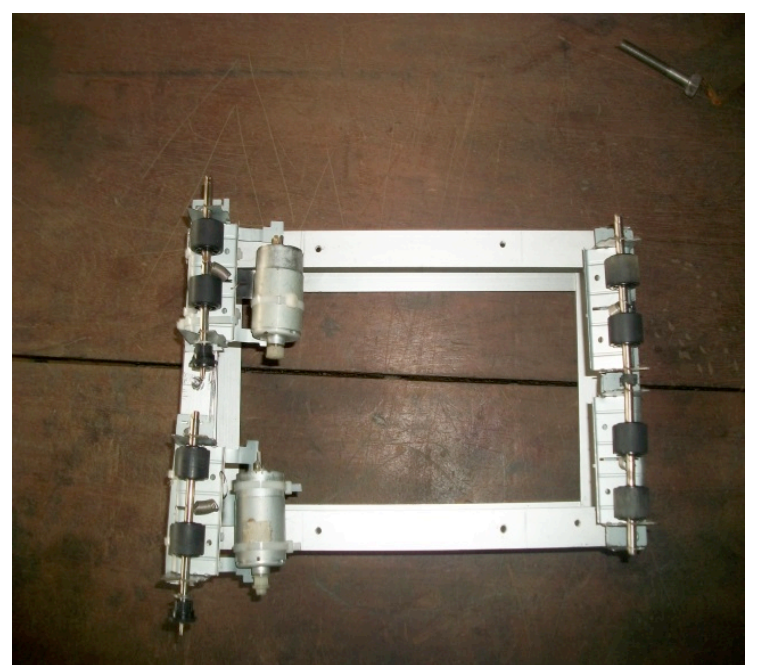

Figura 2: Visão inferior do VTNT.

O conjunto eixo de rodas - motor foi fixado em uma barra plana através de parafuso, arruela e porca a estrutura do veículo. A fixação foi feita de forma a permitir um deslocamento do conjunto em $360^{\circ}$. Tal deslocamento permite a rotação do veículo por direções distintas, conforme podemos observar na Figura 3.

Figura 3: VTNT de perfil.

Para viabilizar o controle do veículo foi necessária a realização de um estudo técnico (também chamado de engenharia básica ou levantamento de dados) para verificar todas as necessidades do sistema de controle desejado. Tal estudo serviu como subsídio para a identificação, análise e determinação da melhor estratégia de controle e para a escolha dos recursos de hardware necessários para a sua automação. 
A importância de implantar um sistema de automação pode ser explicada pelos benefícios que são consequências diretas/indiretas de tal sistema, como segurança e diminuição dos riscos de danos ao patrimônio.

A automação do sistema foi feita em duas etapas, que foram desenvolvidas em paralelo. A construção do hardware, confecção do circuito de acionamento dos motores elétricos integrados à plataforma arduino, e a elaboração de uma lógica/linguagem de programação, baseada na linguagem $\mathrm{C++}$, que fosse mais adequada ao propósito do projeto e que servisse para realizar a mobilidade do sistema.

Partindo-se do problema exposto, o primeiro passo para realização da mobilidade do protótipo do VTNT da Figura 4, constitui-se na montagem de um circuito de controle dos motores DC de seu eixo traseiro.

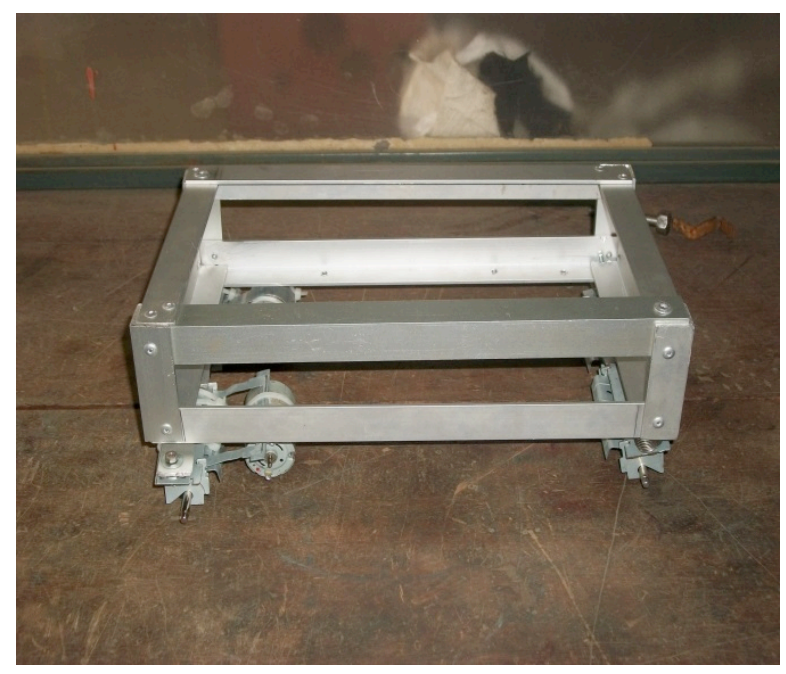

Figura 4: Estrutura física do protótipo do VTNT.

O modelo escolhido para a confeç̧ão do circuito de acionamento dos motores foi baseado na ponte $\mathrm{H}$, pois foi o circuito que apresentou as melhores características de acionamento. Sendo adequado para o controle de velocidade e direção dos motores utilizados, facilitando sua mobilidade durante a realização dos movimentos nas diferentes direções: frente, ré, direita e esquerda.

$\mathrm{Na}$ Figura 5, podemos observar o esquema elétrico da ponte $\mathrm{H}$. Este circuito é muito importante para o desenvolvimento de dispositivos robóticos, pois trata-se de um circuito simplificado capaz de controlar motores de corrente contínua diretamente a partir de sinais elétricos, permitindo desde o controle de sentido de giro até o controle de potência e velocidade. Tem esse nome devido a forma que o circuito assume quando montado. 
Figura 5: Esquema elétrico da ponte $\mathrm{H}$.

Fonte: [6]

$\mathrm{Na}$ construção de uma ponte $\mathrm{H}$ é preciso quatro chaves, que são acionadas de forma alternada. Cada uma deve ficar localizada num extremo e o motor é posicionado no meio. Para o funcionamento do motor, as chaves são acionadas ao par, sempre as chaves diagonalmente opostas. Fazendo com que a corrente elétrica flua do polo positivo para o negativo da fonte, acionando o motor e fazendo-o girar no sentido desejado. Para inverter a rotação do eixo do motor é necessário desligar estas chaves e acionar as outras diagonalmente opostas, assim faremos com que a corrente elétrica flua no sentido oposto, alterando o sentido de rotação do motor. Caso as duas chaves do mesmo lado sejam acionadas simultaneamente, será causado um curto circuito, o que poderá provocar a queima da fonte de alimentação e dos componentes eletrônicos.

Para a confecção da ponte $\mathrm{H}$ são utilizados transistores, pois estes são mais convenientes, devido a sua funcionalidade e fácil aplicação. O transistor é capaz de conduzir corrente entre seus terminais coletor e emissor, quando sua base está devidamente polarizada. No transistor PNP, a corrente será conduzida do emissor para o coletor, já no NPN, a condução da corrente será ao contrário da PNP.

É recomendável a utilização de diodos, na mais diferenciadas configurações do circuito de ponte $\mathrm{H}$, com a finalidade de evitar o fluxo de corrente reversa. Impedindo que a tensão induzida reversa force os transistores.

Para a montagem da ponte $\mathrm{H}$ foi necessário à utilização de relés e transistores $\mathrm{BC}$ 548. Os relés foram ligados aos motores e seu chaveamento é responsável pelo 
controle de direção de rotação dos motores. Para o acionamento dos relés foi necessário a montagem de um circuito amplificador, configuração seguidor de emissor, onde os transistores foram ligados em cascata, formando a configuração Darlington. Através desta configuração o dispositivo, circuito amplificador, é capaz de proporcionar um grande ganho de corrente, vide Figura 6.

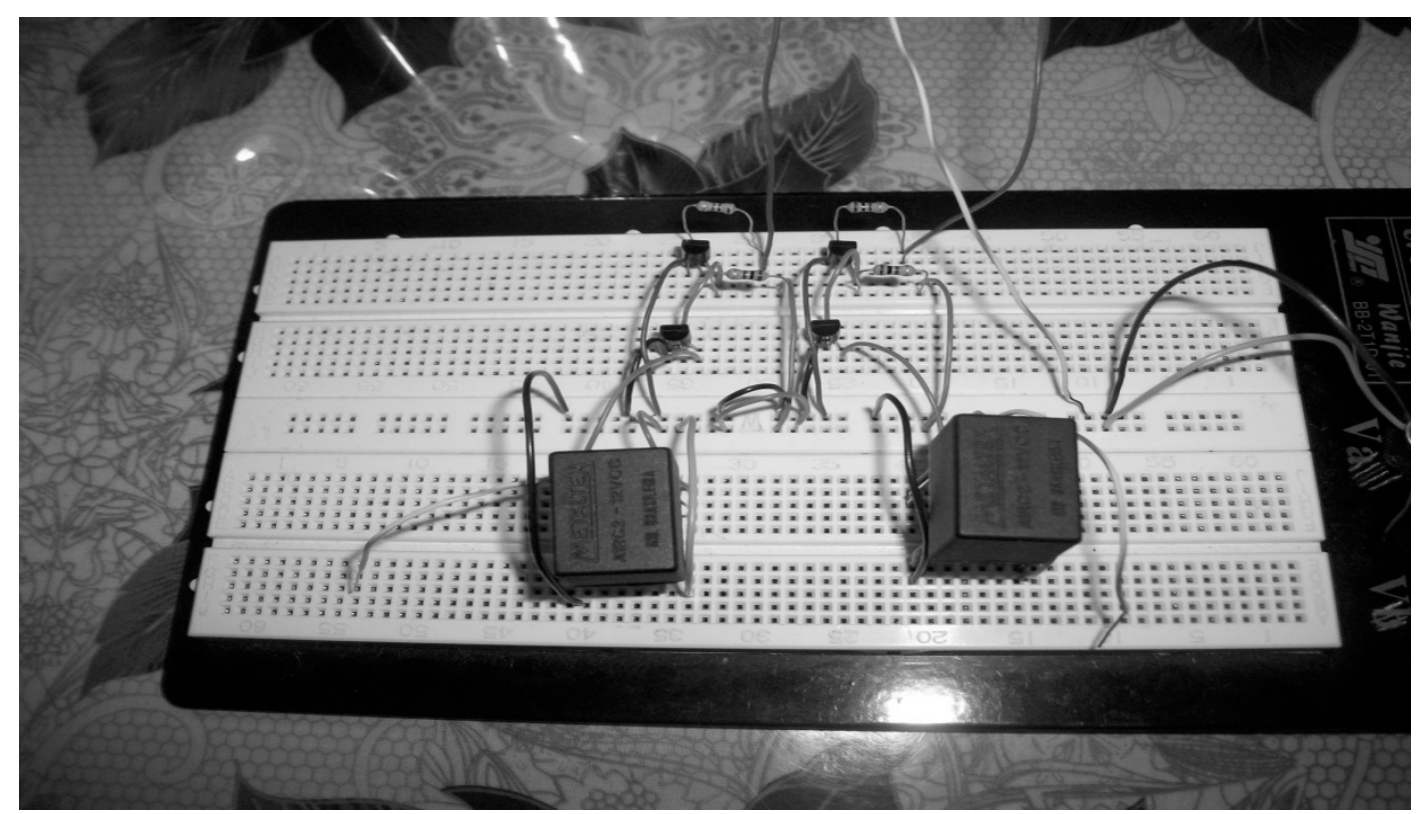

Figura 6: Estrutura física do circuito da ponte $\mathrm{H}$.

3 - Resultados e discussões

Considerando os conceitos supracitados, e partindo da análise e comportamento do circuito do esquemático da Figura 6 foi possível alcançar os objetivos esperados de mobilidade do protótipo.

De acordo com o esquemático abaixo a partir da configuração Darligton dos transistores BC 548, representados na Figura 7 pelas regiões 1 e 2, quando estes são alimentados com uma tensão de entrada da ordem de $5 \mathrm{~V}$ proveniente da fonte, no caso o arduino, obtêm-se uma tensão de saída maior da ordem de $12 \mathrm{~V}$ necessária para energização dos relés, região 3 e 4. Estes quando energizados realizam a função de comutação que permite a saída de energia necessária para ativação do motor (região 9). 


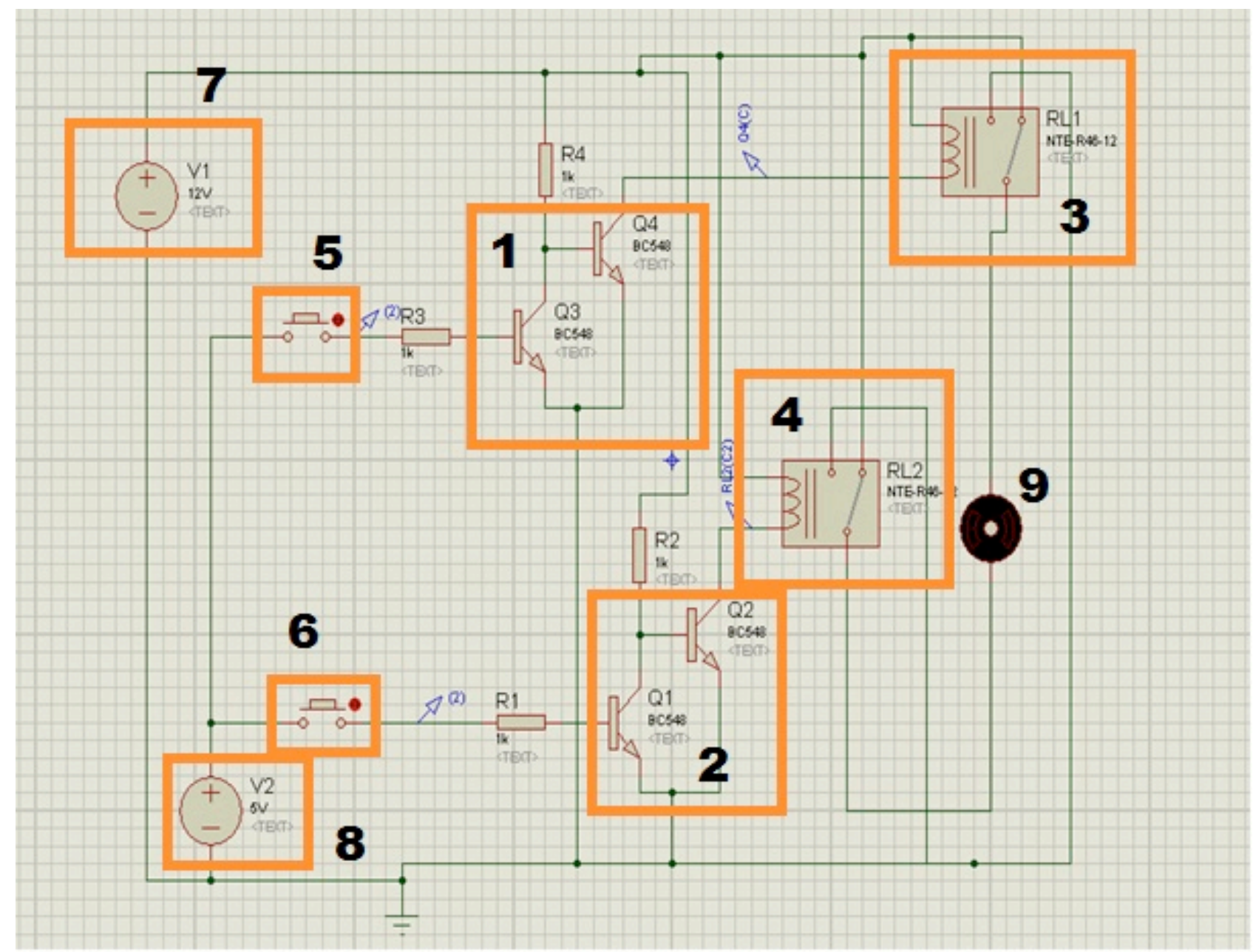

Figura 7: Esquemático do circuito ponte H com relés e a configuração Darligton.

Para a realização da atividade de mobilidade do VTNT nas quatro direções, o motor é ativado a partir do envio dos sinais lógicos $1(H I G H)$ ou 0 (LOW ) enviados pelo arduino através da operação de suas portas digitais fundamentais para o acionamento dos componentes constituintes do circuito da ponte $\mathrm{H}$, Figura 7 , montada no protoboard.

No caso em análise, para a ativação de dois motores DC foram utilizadas 4 portas digitais 5, 6, 10 e 11, sendo essas aos pares sendo uma ligada ao terminal positivo e outra ao negativo de cada um dos motores, vide Figura 8. 


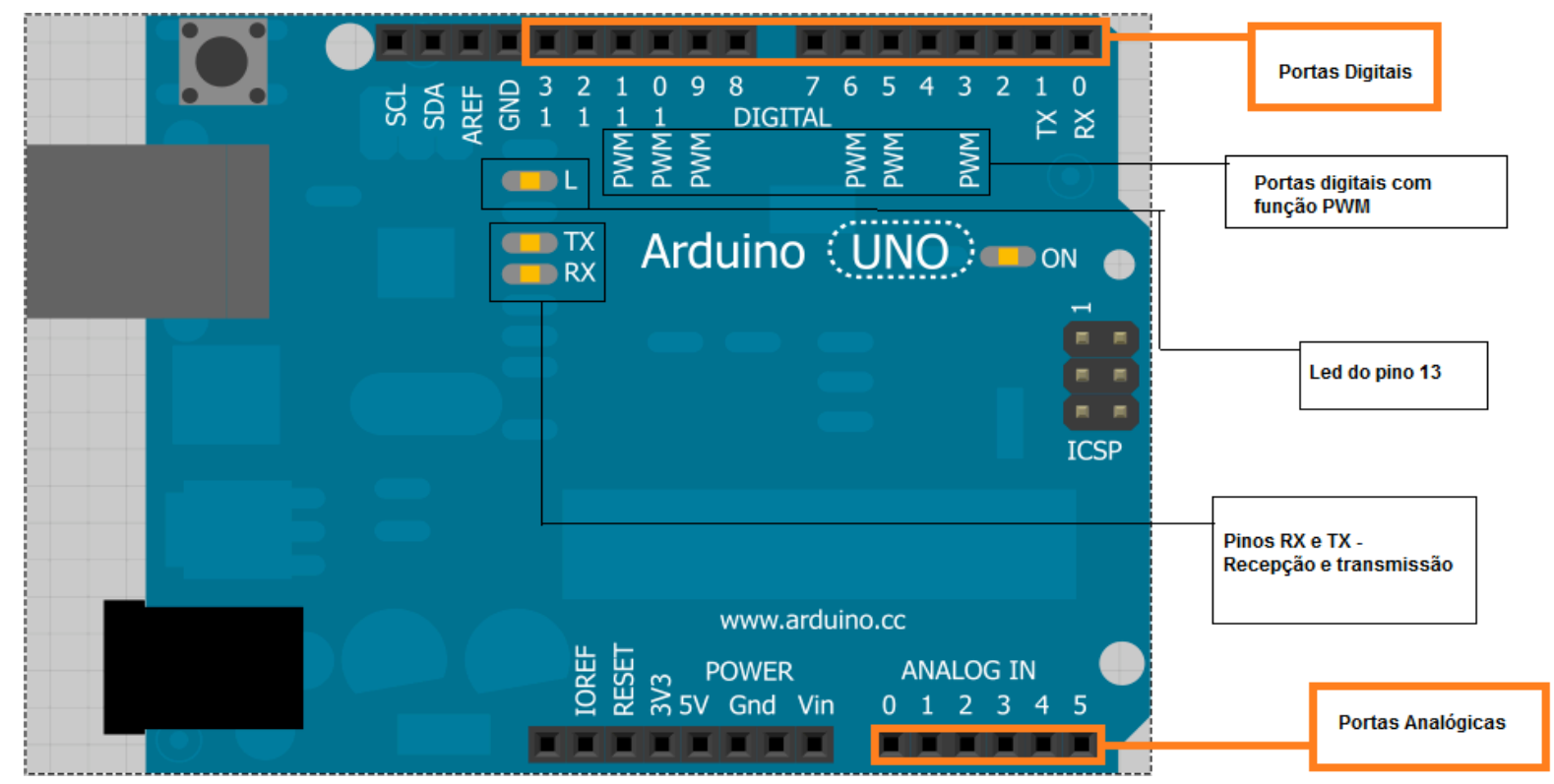

Figura 8: Placa do Arduino

Na seqüência podemos observar o código elaborado para que fosse possível a comunicação entre a plataforma arduino e os motores do VTNT.

void $\operatorname{setup}()\{$

Serial.begin(9600);

pinMode(11, OUTPUT);

pinMode(10, OUTPUT);

pinMode(6, OUTPUT);

pinMode(5, OUTPUT);

\}

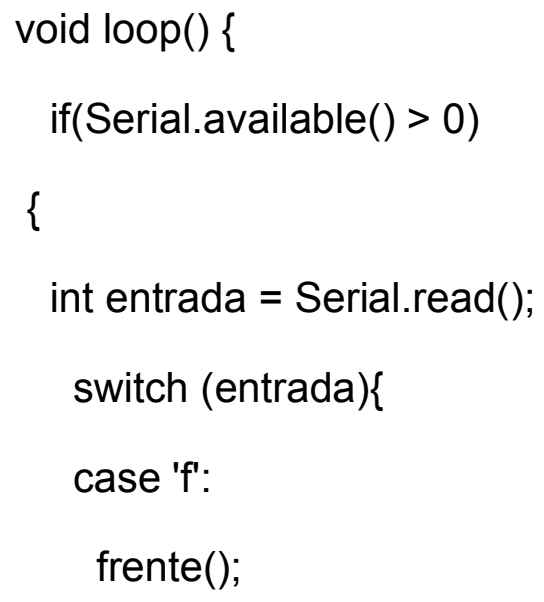




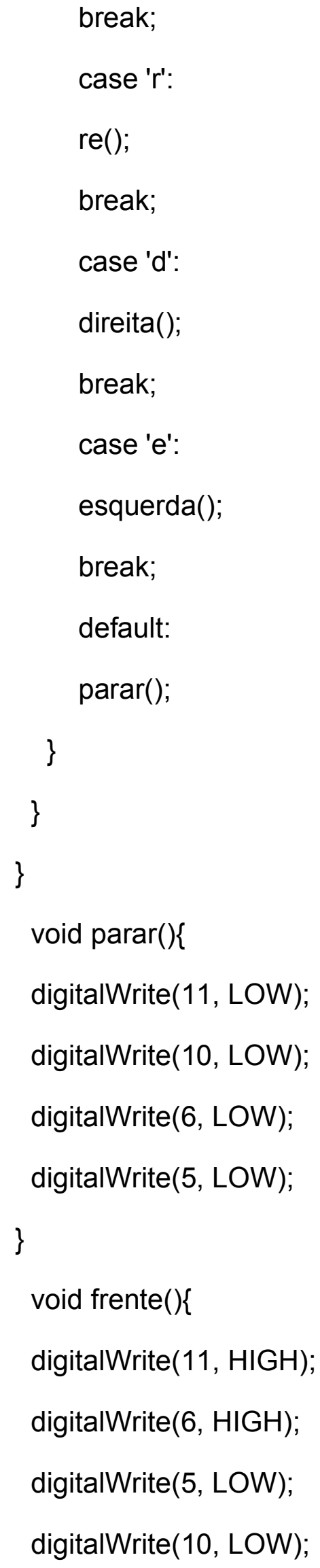




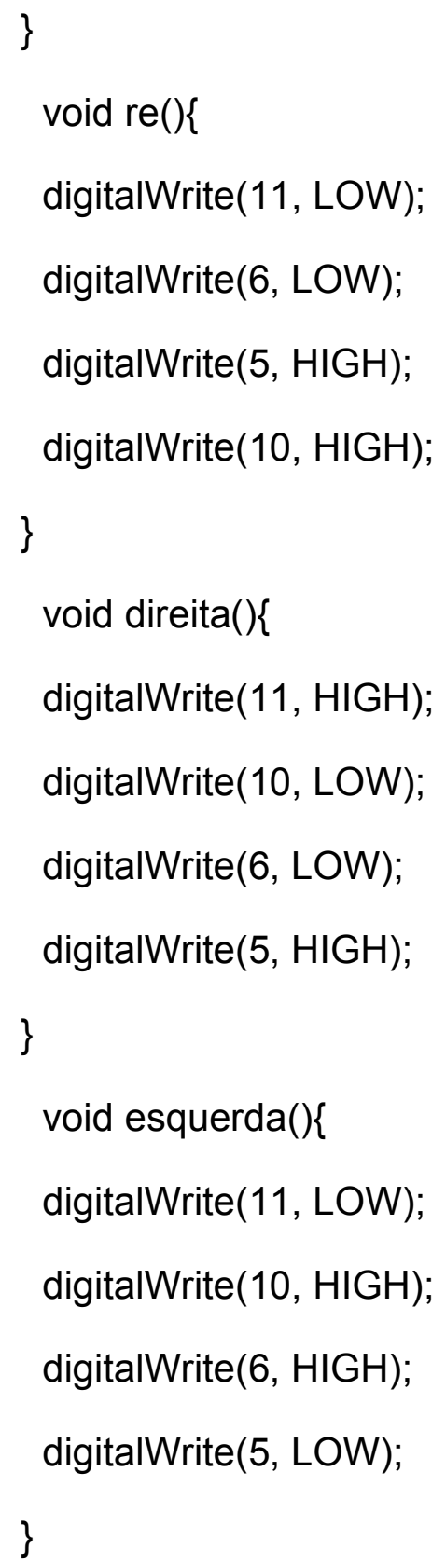

A partir da análise do código supracitado, observa-se que, para realizar a operação de deslocamento frontal são enviados dois sinais HIGH para os terminais positivos e dois sinais LOW para os terminais negativos dos motores. Para a operação de deslocamento traseiro invertem-se os sinais enviados aos terminais positivos e negativos.

Já para as atividades de deslocamento para direita ou esquerda, estas são realizadas a partir da ativação dos motores em sentido contrário, ou seja, se quisermos realizar o deslocamento do VTNT na direção esquerda, aciona-se o motor da esquerda para frente e o da direita para trás. Para o deslocamento na direção direita invertem-se os valores lógicos dos sinais citados acima. 
É importante salientar que o monitoramento das operações é realizado através da alimentação do arduino via um computador que envia as operações de deslocamento do VTNT ao microcontrolador do arduino que envia os sinais pelas portas digitais utilizadas ao circuito da ponte $\mathrm{H}$.

\section{CONCLUSÃO}

Para os VTNTs, a navegação é um obstáculo importante a ser ultrapassada na busca pela autonomia robótica, mas quando você quer que o robô seja capaz de localizar, identificar e desviar dos obstáculos, os desafios são grandes. Descobrir como ensinar um robô a fazer distinções entre os diversos componentes do ambiente em que está inserido poderia demorar muito tempo.

Com base na metodologia proposta, nos resultados obtidos e com a conjuntura de investimentos em pesquisas que vem realizando-se nos mais diferenciados centros de ensino do Brasil, conclui-se que é viável a construção de VTNT, a partir da utilização de materiais acessíveis, oriundos de descartes de objetos eletrônicos e do uso da plataforma de programação arduino. Os primeiros, por serem materiais que na grande maioria das vezes possuem componentes aproveitáveis, por não apresentarem exaustão total dos mesmos, e o último pelo fato de constituir-se em um projeto de open source, o que permite liberdade para realização das atividades do usuário. Essas características tornam-se fundamentais no processo de elaboração de projetos que buscam a união entre eficiência, rendimento e baixo custo.

\section{REFERÊNCIAS}

[1] PAZOS, F. Automação de Sistemas e Robótica. Rio de Janeiro: Editora Axcel Books, 2002.

[2] DORF, R. C. Sistemas de controle Modernos. Rio de Janeiro: LTC editora, $11^{a}$ edição, 1998.

[3] CORADIN, P. Poli desenvolve veículos subaquáticos não tripulados.

Disponível em: http://www5.usp.br/24345/poli-desenvolve-veiculos-subaquaticosnao-tripulados/. Acesso em: 10/04/2013.

[4] Veículos Aéreos Não Tripulados. Disponível em: http://www.fab.mil.br/portal/capa/index.php. Acesso em: 28/04/2013.

[5] Alunos e professores do ES desenvolvem carro que anda sozinho.

Disponível em: http://g1.globo.com/espirito-santo/noticia/2013/04/alunos-eprofessores-do-es-desenvolvem-carro-que-anda-sozinho.html. Acesso em: 20/04/2013.

[6] MORAES, M. Ponte H - Controle de Motores DC. Disponível em: http://arduinobymyself.blogspot.com.br/2012/08/ponte-h-controle-de-motoresdc.html. Acesso em: 20/04/2013. 